\title{
Subdissociative Dose Ketamine Produces a Deficit in Manipulation but not Maintenance of the Contents of Working Memory
}

\author{
Rebekah AE Honey', Danielle C Turner', Garry D Honey', Sam R Sharar², D Kumaran', E Pomarol-Clotet', \\ P McKenna', BJ Sahakian', TW Robbins ${ }^{3}$ and PC Fletcher*, \\ 'Department of Psychiatry, University of Cambridge, Cambridge, UK; ${ }^{2}$ Department of Anesthesiology, Harbonview Medical Center, University of \\ Washington, Cambridge, UK; ${ }^{3}$ Department of Experimental Psychology, University of Cambridge, Cambridge, UK
}

\begin{abstract}
We investigated the effects of subdissociative dose ketamine on executive processes during a working memory task. A total of I I healthy volunteers participated in a double-blind, placebo-controlled, randomized, within-subjects study. They attended on three occasions, receiving intravenous infusions of placebo, a lower ketamine dose, and a higher ketamine dose. On each occasion, they underwent a series of tasks engaging working memory function in verbal and visuo-spatial domains. Further tasks explored aspects of long-term memory, planning, attention, and perceptual processing. With respect to working memory/executive function, a highly specific pattern of impairment was observed. Impairments were seen only at the higher dose of ketamine and restricted to a subgroup of the verbal working memory tasks: While visuo-spatial working memory showed no evidence of impairment, and while simple maintenance processes during verbal working memory were also unimpaired, higher dose ketamine produced a significant impairment in the manipulation of information within working memory. This process-specific effect of ketamine was reflected in a drug-by-task interaction. The specificity of this ketamine effect suggests that the earliest effect of NMDA receptor blockade is in higher order control of executive function rather than in more basic maintenance processes.

Neuropsychopharmacology (2003) 28, 2037-2044, advance online publication, 30 July 2003; doi: I 0. I 038/sj.npp. 1300272
\end{abstract}

Keywords: ketamine; schizophrenia; working memory; psychopharmacology; executive

\section{INTRODUCTION}

The validity of a neurotransmitter system theory of schizophrenia may be tested by observing the effects of challenging that system pharmacologically. If the effects of this challenge are comparable to those seen in patients, this may be indirect evidence of the involvement of the system in the disease. Observations that n-methyl-Daspartate (NMDA) antagonists, such as phenylcyclidine (PCP) and ketamine, produce psychotic symptoms resembling those of schizophrenia have led to an increasing focus on the NMDA receptor hypofunction (NRH) model of schizophrenia (Carlsson et al, 1999; Hirsch et al, 1997; Javitt and Zukin, 1991; Krystal et al, 1999; Tamminga, 1998). Symptoms produced by NMDA antagonists include both

\footnotetext{
*Correspondence: Dr PC Fletcher, Department of Psychiatry, University of Cambridge, Box 255, Addenbrooke's Hospital, Cambridge CB2 2QQ, UK, Tel: + 441223336 988, Fax: + 441223336 58I, E-mail: pcf22@cam.ac.uk

Received 29 January 2003; revised II April 2003; accepted 06 June 2003

Online publication: 19 June 2003 at http://www.acnp.org/citations/ Npp0619030304 I/default.pdf
}

positive and negative psychotic symptoms (Jentsch and Roth, 1999; Krystal et al, 1994, 1999; Lahti et al, 1995, 2001; Malhotra et al, 1996, 1997) as well as the cognitive deficits that frequently accompany these symptoms in schizophrenia (Jentsch and Roth, 1999; Newcomer et al, 1999). The purpose of the current study was to evaluate further the cognitive effects of the NMDA antagonist ketamine with a view to understanding how they may relate to those seen in the disease.

The administration of ketamine has produced impairments in a number of tasks thought to engage executive/ frontal lobe function: verbal working memory (Adler et al, 1998), Wisconsin Card Sorting Test (WCST) (Hetem et al, 2000; Krystal et al, 2000), and verbal fluency (Adler et al, 1998; Hetem et al, 2000). However, other studies incorporating tests of executive function have failed to find any effect of ketamine on working memory tasks (Ghoneim et al, 1985; Harriset al, 1975; Malhotra et al, 1996, 1997; Newcomer et al, 1999), verbal fluency (LaPorte et al, 1996; Newcomer et al, 1999; Radant et al, 1998), and Trailmaking B and Stroop tasks (Harborne et al, 1996).

Inconsistencies in the nature of any executive dysfunction associated with ketamine may be due to inconsistencies in 
the assessment tasks or to differences in the ketamine administration protocols. At present, however, the basis for these discrepancies is not clear. For example, with respect to verbal fluency, an impairment was found in studies where subjects received computerized infusions of ketamine targeted to plasma levels of $150 \mathrm{ng} / \mathrm{ml}$ (Hetem et al, 2000) and noncomputerized bolus + infusion ketamine administration to plasma levels of approximately $90 \mathrm{ng} / \mathrm{ml}$ (Adler et al, 1998; Breier et al, 1997). However, no effect on verbal fluency was found in other studies in which subjects were administered simple bolus + infusion doses of ketamine resulting in measured plasma levels of $20-110 \mathrm{ng} / \mathrm{ml}$ (Newcomer et al, 1999), measured plasma levels of $50-200 \mathrm{ng} / \mathrm{ml}$ (Radant et al, 1998), or estimated plasma levels of 150 $250 \mathrm{ng} / \mathrm{ml}$ (LaPorte et al, 1996). Thus, the inconsistency in results cannot be attributed simply to either task or drug dose. It may result from variations in subject characteristics, or from the fact that executive tasks rely on a number of different processes that may not all be affected by ketamine. It may be possible, for example, to switch strategies, meeting task demands through the use of other processes - an approach adopted, perhaps, by some subjects but not others.

The aim of this study was to focus on particular aspects of executive function, namely working memory and planning, and to identify more specifically, the nature of the impairment, if any, produced by a continuous infusion of ketamine targeted to a particular plasma concentration. We wished to characterize the effects of ketamine at levels that did not produce marked psychotic symptoms since these, in themselves, might prove sufficiently distracting to make the measures of executive function difficult to interpret. We therefore administered subdissociative dose infusions of ketamine (targeted to plasma levels of 50 and $100 \mathrm{ng} / \mathrm{ml}$ ). Both maintenance and manipulation processes in working memory were assessed across a range of presentation modalities (digits, letters, and visuospatial) in order to identify the specific areas of any deficit.

\section{METHOD}

\section{Participants}

A total of 13 healthy volunteers (six males, seven females) each attended on three occasions ( $48 \mathrm{~h}$ apart). Participants had a mean age of 32.6 years (range 18-64) and a mean estimated IQ of 97.54 (SD 27.79) as predicted by the National Adult Reading Test (NART; Nelson, 1991). All had a body mass index within $10 \%$ of their ideal weight, and all spoke English as their primary language. Exclusion criteria included the presence or history of psychotic symptoms, as well as family history of psychosis and history of drug or alcohol abuse. Participants were recruited by advertisement and reimbursed for travel costs and their time. Informed written consent was obtained and the study was approved by the local hospital research ethical committee. Two subjects were excluded from the final analysis: one because, during testing, it became apparent that he was dyslexic; one subject because of partial extravascular drug infusion during one of the ketamine sessions. Consequently, data are reported on 11 subjects.

\section{Assessment of Executive Function}

Verbal working memory. Two tests of verbal working memory were used. One was a forward and backward digit span from the Wechsler Adult Intelligence Scale, 3rd edition (WAIS-III). Two parallel versions of digit span were created using randomly generated numbers. A further test of verbal working memory based on a test devised by D'Esposito et al (1999) required participants to recall a series of letters either in the order presented (maintenance condition), or to re-order the letters into alphabetical order and remember the new order (manipulation condition).

Spatial working memory. Spatial working memory was assessed using the Spatial Span and Spatial Working Memory tests from the CANTAB battery (www.camcog.com). The Spatial Span task is a computerized version of Corsi's block tapping test and provides a measure of spatial memory span (Owen et al, 1990; Sahakian and Owen, 1992; Robbins et al, 1994). Spatial Span is a test of the ability to recall the order in which a series of boxes were highlighted. The important measures for this task are span length and total errors. Spatial Working Memory is a test of spatial working memory and strategy performance to find individually hidden 'blue tokens' without returning to a box where one has previously been found. The important measures from this task are: Strategy Score; total between errors (returning to a box where a token has been found); and total within errors (returning to a box that has already been inspected).

Planning. Planning was assessed using the 6-box One-touch Tower of London task from the CANTAB battery. This task was modified from the original CANTAB Tower of London task. The One-touch Tower of London task is a spatial planning test, involving planning a sequence of moves to achieve a goal arrangement of colored balls without moving the balls (Owen et al, 1995). The important measures for this task are perfect completions and latency (ms).

\section{Control Measures}

Line orientation. The Line Orientation subtest from the Repeatable Battery for the Assessment of Neuropsychological Status (Randolph, 1998) was used to check for changes to visual perception resulting from ketamine. Participants were presented with an array of 13 orientations across $180^{\circ}$ and were asked to choose the lines from this array matching two target lines. There were 10 trials with a score range of 0 20 (1 point for each correct response).

Subjective rating scales/thought disorder. During the infusion, patients were interviewed clinically using an abbreviated form of the Present State Examination, 9th Edition (PSE-9, Wing et al, 1974) designed to cover symptoms relevant to ketamine effects (the whole interview was not administered since time was limited as we wished to minimize the amount of time subjects were on drug). The following symptoms were explored: tiredness, muscular tension, subjective feelings of nervous tension, anxiety, subjectively inefficient thinking, poor concentration, depressed mood, expansive mood, subjective ideomotor 
pressure, derealization, depersonalization, delusional mood, heightened, dulled, and changed perception, changed perception of time, ideas and delusions of reference, and hallucinations. Patients were also recorded speaking for approximately $10 \mathrm{~min}$, first describing a recent experience, then telling a fairy story and then explaining a number of cartoons. The speech was recorded and later rated on the Thought, Language and Communication Scale (TLC; Andreasen 1986). All clinical ratings were made blind to dosage of ketamine.

\section{Procedure}

The study was a double-blind, placebo-controlled, randomized, within subjects comparison of targeted steady-state plasma levels of ketamine administered by continuous intravenous (i.v.) infusion. For safety reasons, a clinician who was not involved in test administration was aware of the study drug and dose being administered on each session. Across their three visits, subjects received saline placebo, a lower dose ketamine infusion, and a higher dose ketamine infusion, the order of these infusions being randomized.

Prior to testing, bilateral forearm i.v. catheters were inserted, one for ketamine infusion, the other for serial blood sampling for plasma ketamine levels. Racemic ketamine ( $1 \mathrm{mg} / \mathrm{ml}$ solution) was administered by bolus and continuous infusion using a computerized pump (Graseby 3500, Graseby Medical Ltd, UK). The pump was programmed (Anaetech Ltd, UK) to deliver a rapid bolus dose $(<60 \mathrm{~s})$ followed by varying infusion rates in order to achieve constant estimated target plasma concentrations of 50 or $100 \mathrm{ng} / \mathrm{ml}$ within $2 \mathrm{~min}$, using pharmacokinetic parameters of a three-compartment model described by Domino et al (1982). Blinding of each subject and the investigator performing the clinical assessments was assured by use of the same infusion pump and pump adjustment schedule on all three study days (saline infusion on placebo day, ketamine infusions for the two intervention days) programmed by a single investigator not involved in clinical or cognitive assessment.

Simulations of plasma and effect-site (brain) concentrations of drugs with similar pharmacokinetics and effects (midazolam and propofol) suggest that plasma and effectsite concentrations equilibrate by $5 \mathrm{~min}$ following bolus administration (Gepts, 1998). Thus, behavioral testing began at least 5 min following initial study drug administration with digit span followed by line orientation and the CANTAB tasks (Spatial Working Memory, Spatial Span, and Tower of London) in pseudorandom order. A sustained attention task and a series of long-term memory tasks were carried out through the course of each visit. These are reported elsewhere. A modified version of D'Esposito et al's (1999) verbal working memory task was administered (approximately $80 \mathrm{~min}$ following start of infusion) (see Figure 1).

Peripheral venous blood samples were drawn 10 min after testing started (15 min after beginning ketamine administration (Time 1), and at the end of testing (approximately 110 min after beginning ketamine administration (Time 2) (see Figure 1). Blood samples were placed on ice, plasma obtained by centrifugation, and plasma samples stored at $-20^{\circ} \mathrm{C}$. Ketamine levels were measured by gas chromatography-mass spectrometry as previously described (Kharasch and Labroo, 1992).

\section{Data Analysis}

Data were analyzed using repeated measures analyses of variance (ANOVAs). For the verbal working memory tasks, a $2 \times 2 \times 3$ design was used with drug level (placebo vs lower dose ketamine vs higher dose ketamine), material (words vs numbers), and task type (maintenance vs manipulation) as the independent variables. One-way repeated measures ANOVAs were conducted for the CANTAB tasks. Sphericity was assessed and the Greenhouse-Geisser conservative F-test was used to interpret the ANOVA where necessary.

Repeated measures ANOVAs were also conducted using session as the independent variable in order to assess any practice effects.

\section{RESULTS}

\section{Plasma Levels}

At Time 2 (predicted steady state), measurement closely approximated the levels predicted by the pharmacokinetic model with a mean of $54.6 \mathrm{ng} / \mathrm{ml}(\mathrm{SD}=10.4)$ in the lower dose condition and $106.8 \mathrm{ng} / \mathrm{ml}(\mathrm{SD}=22.1)$ in the higher dose condition.

The plasma levels at Time 1 were substantially lower than those predicted by the model with a mean of $32.5 \mathrm{ng} / \mathrm{ml}$ $(\mathrm{SD}=12.4)$ in the lower dose condition and a mean of $64.4 \mathrm{ng} / \mathrm{ml}(\mathrm{SD}=24.1)$ in the higher dose condition. This has strongest implications for the results of the digit span tasks since these were always administered shortly after the initial 'loading' of study drug, at the approximate time of the first blood sampling. We therefore explored this further by evaluating the correlation between plasma levels at Time 1 and performance on the digit span tasks. There was no significant relationship between plasma levels at Time 1 and digit span performance including forward span on lower dose ketamine $(r=0.0005, p>0.05)$, backward span on lower dose ketamine $(r=0.06, p>0.05)$, forward span on higher dose ketamine $(r=-0.26, p>0.05)$, and backward span on higher dose ketamine $(r=-0.35, p>0.05)$.

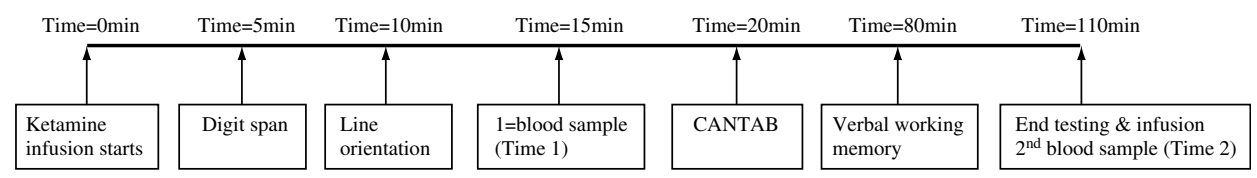

Figure I Timeline demonstrating the timing of tasks, ketamine infusion, and blood samples during the study. 


\section{Control Measures}

Line orientation. A one-way repeated measures ANOVA investigating line orientation performance across different plasma levels of ketamine failed to find any significant effect, $\mathrm{F}(2,22)=0.30, p>0.05$.

Subjective ratings scales and thought disorder. The ratings from the PSE-9 are presented in Table 1. The subjects showed a dose-dependent increase in symptoms. Most of the subjective symptoms were either nonspecific (eg tiredness, inefficient thinking, poor concentration), or typical ketamine effects (eg expansive mood, heightened perception, changed perception). Three subjects reported ideas or delusions of reference. No subject experienced hallucinations. Only three subjects showed any more than questionable evidence of thought disorder using the TLC scale, which was barely evident in all cases: Two subjects were rated as having mild poverty of content of speech during the high ketamine condition. One subject showed circumstantiality while receiving placebo, which increased on higher dose ketamine and was accompanied by derailment.

\section{Cognitive Tasks}

Verbal working memory. Figure 2 presents the results of verbal working memory. A $2 \times 2 \times 3$ repeated measures ANOVA, using plasma levels at time 1 as a covariate, revealed a significant drug-by-task type interaction, $\mathrm{F}(2,20)=5.31, p<0.05$. Post hoc comparisons exploring this interaction showed that performance on the manipulation condition of the verbal working memory tasks was significantly worse for the higher dose of ketamine than placebo, $\mathrm{F}(1,10)=13.86, p<0.05$. A $2 \times 2 \times 3$ repeated measures ANOVA using session as the independent variable failed to show any effect of session on performance, $\mathrm{F}(2,20)=0.27, p>0.05$.

Spatial working memory and planning. Table 2 presents the results of the CANTAB measures. A series of one-way

\section{Table I}

\begin{tabular}{|c|c|c|c|}
\hline Subscale & Placebc & $n g / r$ & $0 \mathrm{ng} / \mathrm{ml}$ \\
\hline Tiredness & 2 & 3 & 6 \\
\hline 'Nervous tension' & - & - & 2 \\
\hline Autonomic anxiety & - & । & - \\
\hline Subjectively inefficient thinking & 2 & 6 & 11 \\
\hline Poor concentration & 2 & 6 & 11 \\
\hline Depressed mood & I & - & I \\
\hline Expansive mood & 2 & 3 & 9 \\
\hline Subjective ideomotor pressure & । & । & 3 \\
\hline Derealization & - & - & - \\
\hline Depersonalization & - & - & - \\
\hline Delusional mood & - & - & - \\
\hline Heightened perception & - & । & 3 \\
\hline Dulled perception & - & - & - \\
\hline Changed perception & - & - & 2 \\
\hline Changed perception time, deja vu & - & - & - \\
\hline Auditory hallucinations & - & - & - \\
\hline Visual hallucinations & - & - & - \\
\hline Olfactory hallucinations & - & - & - \\
\hline Ideas/delusions of reference/misinterpretation & - & - & 3 \\
\hline
\end{tabular}

Neuropsychopharmacology

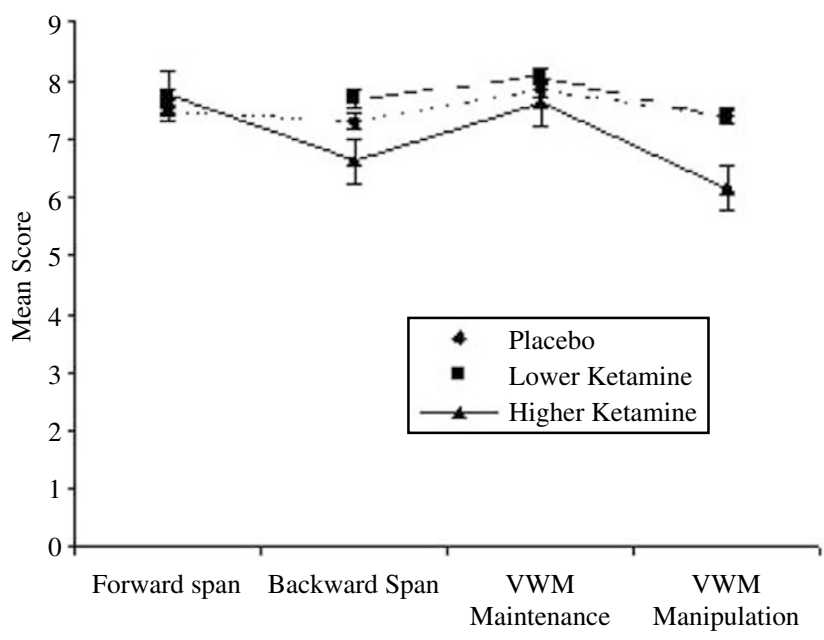

Figure 2 Mean scores ( \pm S.E. mean) of digit span and verbal working memory for placebo, $50 \mathrm{ng} / \mathrm{ml}$ ketamine, and $100 \mathrm{ng} / \mathrm{ml}$ ketamine conditions.

repeated measures ANOVAs, using plasma levels at Time 1 as a covariate, failed to reveal any significant difference between levels of ketamine on any of the CANTAB tasks. One-way repeated measures ANOVAs using session as the independent variable failed to show any effect of practice on performance on spatial span but found some significant practice effects on spatial working memory (six box errors only), $\mathrm{F}=6.48, p<0.05$, and Tower of London for the number of perfect solutions, $\mathrm{F}=5.46, p<0.05$, and for the initial time to move for the one move condition, $F=19.72$, $p<0.05$.

Given the null result for the CANTAB measures, we assessed these tasks on a further six participants in a subsequent study in order to increase the power. No effect was seen with the addition of further subjects.

\section{Summary of Results}

Ketamine produced significant impairment in a particular aspect of verbal working memory function: specifically the requirement to reorganize encoded material (either into reverse order in the case of the digit span or into alphabetical order in the case of letters). This effect was seen only at the higher plasma level, but even this dose was insufficient to produce marked or consistent (across subjects) signs of psychopathology. Furthermore, the manipulation deficit occurred in the face of preserved performance across a range of other tasks engaging highlevel cognitive functions such as planning (Tower of London task) and strategy implementation (spatial working memory task).

\section{DISCUSSION}

This study has produced evidence for a highly specific impairment in the executive control of working memory at a subdissociative plasma level of ketamine. Our confidence in the specificity of this finding comes from a series of observations. First, the impairment was observed solely in the tasks engaging 'higher order' working memory 
Table 2

\begin{tabular}{|c|c|c|c|c|c|}
\hline Measure & Placebo, mean (SD) & $50 \mathrm{ng} / \mathrm{ml}$ ketamine, mean (SD) & $100 \mathrm{ng} / \mathrm{ml}$ ketamine, mean (SD) & F-value & $p$-Value \\
\hline \multicolumn{6}{|l|}{ Spatial Span } \\
\hline Span length & $6.36(1.29)$ & $6.91(1.30)$ & $6.82(1.40)$ & 0.72 & 0.5 \\
\hline Total errors & $13.18(3.95)$ & $16.55(6.35)$ & I $5.73(9.21)$ & 1.87 & 0.18 \\
\hline \multicolumn{6}{|l|}{ Spatial Working Memory } \\
\hline Total between errors & $16.18(11.20)$ & I3.82 (8.90) & $14.00(17.10)$ & 0.08 & 0.93 \\
\hline Between errors ( 6 boxes) & $4.82(5.70)$ & $4.91(4.30)$ & $4.00(7.30)$ & 0.14 & 0.87 \\
\hline Total within errors & $1.91(2.70)$ & $1.91(2.17)$ & $1.30(2.79)$ & 0.4 & 0.67 \\
\hline \multicolumn{6}{|l|}{ Tower of London } \\
\hline Perfect solutions & I $8.82(2.10)$ & $20.55(2.10)$ & $19.36(2.80)$ & 2.54 & 0.1 \\
\hline Initial time (I move) & $9194.29(3703.60)$ & $8982.95(4990.12)$ & $9440.16(2767.73)$ & 0.09 & 0.92 \\
\hline Initial time (2 moves) & $4569.11(1253.78)$ & $4648.96(\mid 408.02)$ & $5262.36(1745.76)$ & 1.25 & 0.31 \\
\hline
\end{tabular}

processes, that is, the requirement to manipulate the contents of working memory rather than simply to encode and maintain a series of items. In fact, there was no evidence that subjects' ability simply to maintain information was impaired. This process specificity was reflected in a significant drug-by-task interaction. Our task design was sufficiently flexible to elucidate a deficit in maintenance processes, since all subjects were tested to the limit of their span. This supports the specificity of the manipulation deficit and suggests that it was not due simply to increased difficulty or load. Similarly, other tasks in the battery that were described as difficult by subjects, for example, Tower of London, were not selectively impaired on ketamine. Second, the effect found here was both domain- and process-specific: domain-specific in that engagement of an analogous process in a visuo-spatial working memory task was not measurably impaired by ketamine; process-specific in that tasks engaging other aspects of executive function were also unaffected. However, we make these observations with caution since there are a number of other possible reasons for the absence of impairments in the other tasks. These will be discussed below. Finally, this impairment was not directly attributable to the psychotomimetic effects of ketamine. Such effects were not prominent, other than some drowsiness and mild elevation in mood, even at the higher dose administered. Although the PSE-9 showed some changes associated with ketamine administration, there was no evidence of florid psychosis in the form of hallucinations, and only three subjects exhibited mild delusional thinking. Formal thought disorder symptoms were not prominent in participants following ketamine administration: only three subjects showed evidence of thought disorder and in these cases it was mild.

The verbal working memory task was based on that developed by D'Esposito et al (1999) for use in a functional neuroimaging setting. We consider it analogous to another imaging-based working memory task that exercises processes involved in the updating and manipulation of the contents of working memory - the n-back task (Braver et al, 1997; Jonides et al, 1997). In addition, it is comparable to memory tasks developed by Petrides et al (1993), held to engage 'monitoring' processes. Common to all tasks is a requirement to go beyond simple maintenance of material and to generate responses on the basis of an internal updating or manipulation of working memory contents. By this we mean that, when a subject is presented with a letter string to be put into alphabetical order or a digit string to reverse, they must go through a series of operations in which the maintained string must be searched iteratively to find the items that appear first, second, third, etc in the new string. Throughout these operations, subjects must maintain and update a schema that features all items in the original string that have been assigned a new position in the list and those that have yet to be reassigned. We are unable, on the basis of the current observations, to speculate upon whether the effect of ketamine was specific to any particular type of process (eg updating, manipulating, monitoring). However, it is compelling, nevertheless, that the effects relate to the control of, rather than the contents of, working memory. Although we have interpreted these results as indicating a deficit in executive function, we must also acknowledge that other processes (eg visual) are involved in this task and that the drug may preferentially affect these. We do not believe that such effects may account for our findings, in view of the fact that subjects reported no visual problems on the drug and that performance on other tasks, specifically designed to elucidate the presence of perceptual abnormalities, was unimpaired. The extent to which this finding provides evidence for ketamine as a model for schizophrenia is, of course, limited. In part, this is due to the fact that our desire to constrain our investigation to subdissociative levels of ketamine has meant that we are in effect dealing with a truncated dose-response curve. However, we believe that some parallels with schizophrenia may be drawn, albeit tentatively. Patients with schizophrenia exhibit working memory deficits, particularly central executive deficits (Bressi et al, 1996; Mahurin et al, 1998; McGrath et al, 1997; Morice and Delahunty, 1996). However, these patients also tended to show deficits in the maintenance, as well as the manipulation of informa- 
tion, although the effect on manipulation was stronger (Conklin et al, 2000; Stone et al, 1998; Tek et al, 2002). Arguably, the cognitive impairments apparent in subjects on very low acute doses of ketamine represent precursors to the full cognitive impairment apparent in schizophrenia. In chronic schizophrenia, such subtle cognitive effects may be swamped by the extent of cognitive impairment present in the condition. Even with respect to acute psychosis in firstepisode schizophrenia, the extent of the psychosis and cognitive impairment is such that subtle patterns of impairment may be lost (cf Joyce et al, 2002). Interestingly, neuropsychological assessments of relatives have shown impairments in executive tasks such as verbal fluency (Cosway et al, 2000; Egan et al, 2001), the Hayling test (Cosway et al, 2000), WCST (Egan et al, 2001), and Trails B (Egan et al, 2001). However, the particular nature of these deficits has not been clearly specified. We suggest that the cognitive impairments associated with the plasma levels of ketamine assessed in the current study are more akin to those found in relatives of patients with schizophrenia than in either chronic or acute patients.

The finding provides some indirect evidence for the functional neuroanatomical correlates of the ketamine effect. Imaging research suggests that manipulation processes involve the dorsolateral prefrontal cortex (PFC), while maintenance processes involve the ventrolateral prefrontal cortex (Collette et al, 1999; D'Esposito et al, 1999; Owen et al, 1996; Smith et al, 1996). Likewise, in other neuroimaging studies that have engaged similar processes, dorsolateral PFC activation is prominent (see Fletcher and Henson, 2001 for review). The emerging pattern of functional neuroimaging findings from both episodic and working memory led Fletcher and Henson to suggest that dorsolateral PFC is associated with tasks that require 'selection from, or refinement of, information that is maintained on-line together with on-going evaluation of the sufficiency of that information for the current task'. This view of dorsolateral function is an extension of that of Petrides (1998) and is plausibly descriptive of the processes engaged by our manipulation task, the processes that seem especially vulnerable to a subpsychotic dose of ketamine. Perhaps we might speculate, therefore, that ketamine has an effect upon dorsolateral frontally mediated processes, a finding that is, of course, relevant to views positing a dorsolateral PFC deficit in schizophrenia (Manoach et al, 2000; Volz et al, 1999).

With respect to visuo-spatial working memory and planning, the results of this study are inconclusive. There was no apparent effect of ketamine on executive processes as measured by the visuo-spatial working memory task, or on planning processes as measured by the Tower of London task, even when data from extra subjects were added. However, this does not rule out the possibility that our study was underpowered with respect to these tasks. To conclude so would be to accept the null hypothesis. Furthermore, the practice effects, though they were weak, may have occluded any effect of ketamine. Finally, the analogy between the spatial working memory task and the verbal working memory task is not entirely compelling. While, like the verbal manipulation tasks, the spatial working memory task requires manipulation, monitoring, and updating of information held in working memory, the similarity between the tasks is likely to be only partial. Thus, the observations may not reflect true domain specificity. It is noteworthy that, with respect to spatial span, there was no practice effect and no effect of ketamine. This is consistent with the absence of a ketamine effect on maintenance in verbal memory. Further studies investigating executive processes in the visuo-spatial domain using tasks that are more suitable for repeated administration are warranted.

The results of the serially measured ketamine plasma levels have interesting implications for the interpretation of the results of this and other studies. By using the method of target-controlled ketamine infusion, our intention was to improve the accuracy of our results by performing task assessment at constant plasma ketamine levels as predicted by a programmed pharmacokinetic model. In the current study, there was considerable intersubject variability in ketamine levels, particularly within $20 \mathrm{~min}$ of initiating the ketamine infusion. This suggests that the rate of change in ketamine level varied between subjects and this may have had an effect on the performance on some tasks. However, in the current study, the lack of any significant correlation between ketamine levels and performance on digit span (the first task) suggests that this variability did not affect performance on the verbal working memory tasks.

In conclusion, these results show that ketamine, at a subdissociative plasma level, disrupts central executive processes in verbal working memory. This effect is specific to executive processes, such as manipulation of information, and is not evident in maintenance processes. The current study failed to find an effect of ketamine on executive processes in visuo-spatial memory or planning.

\section{ACKNOWLEDGEMENTS}

Supported by the Wellcome Trust and the Wellcome Trust Clinical Research Facility, Addenbrooke's Hospital, Cambridge. Completed within the MRC Centre for Behavioural and Clinical Neuroscience. $\mathrm{CO}^{\prime} \mathrm{L}$ carried out this work under the tenure of a research SHO post on the Cambridge psychiatry training rotation. We are very grateful to Irene Tracey and Richard Rogers (FMRIB, Oxford University).

\section{REFERENCES}

Adler CM, Goldberg TE, Malhotra AK, Pickar D, Breier A (1998). Effects of ketamine on thought disorder, working memory, and semantic memory in healthy volunteers. Biol Psychiatry 43: 811-816.

Andreasen NC, Grove WM (1986). Thought, language, and communication in schizophrenia: diagnosis and prognosis. Schizophr Bull 12: 348-359.

Braver TS, Cohen JD, Nystrom LE, Jonides J, Smith EE, Noll DC (1997). A parametric study of prefrontal cortex involvement in human working memory. Neuroimage 5: 49-62.

Breier A, Malhotra AK, Pinals DA, Weisenfeld NI, Pickar D (1997). Association of ketamine-induced psychosis with focal activation of the prefrontal cortex in healthy volunteers. Am J Psychiatry 154: 805-811.

Bressi S, Miele L, Bressi C, Astori S, Gimosti E, Linciano AD, Sessini M, Invernizzi GL (1996). Deficit of central executive component of working memory in schizophrenia. New Trends in Experimental and Clinical Psychiatry 12: 243-252. 
Carlsson A, Hansson LO, Waters N, Carlsson ML (1999). A glutamatergic deficiency model of schizophrenia. Br J Psychiatry 174(Suppl 37): 2-6.

Collette F, Salmon E, Van der Linden M, Chicherio C, Belleville S, Degueldre C et al (1999). Regional brain activity during tasks devoted to the central executive of working memory. Cognitive Brain Res 7: 411-417.

Conklin HM, Curtis CE, Katsanis J, Iacono WG (2000). Verbal working memory impairment in schizophrenia patients and their first-degree relatives: evidence from the digit span task. Am J Psychiatry 157: 275-277.

Cosway R, Byrne M, Clafferty R, Hodges A, Grant E, Abukmeil SS et al (2000). Neuropsychological change in young people at high risk for schizophrenia: results from the first two neuropsychological assessments of the Edinburgh High Risk Study. Psychol Med 30: 1111-1121.

D’Esposito M, Postle BR, Ballard D, Lease J (1999). Maintenance versus manipulation of information held in working memory: an event-related fMRI study. Brain Cognition 41: 66-86.

Domino EF, Zsigmond EK, Domino LE, Domino KE, Kothary SP, Domino SE (1982). Plasma levels of ketamine and two of its metabolites in surgical patients using a gas chromatographic mass fragmentographic assay. Anesth Analg 61: 87-92.

Egan MF, Goldberg TE, Gscheidle T, Weirich M, Rawlings R, Hyde TM et al (2001). Relative risk for cognitive impairments in siblings of patients with schizophrenia. Biol Psychiatry 50: 98-107.

Fletcher PC, Henson RNA (2001). Frontal lobes and human memory: insights from functional neuroimaging. Brain 124: 849-881.

Gepts E (1998). Pharmacokinetic concepts for TCI anaesthesia. Anaesthesia 53(Suppl 1): 4-12.

Ghoneim MM, Hinrichs JV, Mewaldt SP, Petersen RC (1985). Ketamine: behavioral effects of subanesthetic doses. J Clin Psychopharmacol 5: 70-77.

Harborne GC, Watson FL, Healy DT, Groves L (1996). The effects of sub-anaesthetic doses of ketamine on memory, cognitive performance and subjective experience in healthy volunteers. $J$ Psychopharmacol 10: 134-140.

Harris JA, Biersner RJ, Edwards D, Bailey LW (1975). Attention, learning, and personality during ketamine emergence: a pilot study. Anesth Analg 54: 169-172.

Hetem LAB, Danion JM, Diemunsch P, Brandt C (2000). Effect of a subanesthetic dose of ketamine on memory and conscious awareness in healthy volunteers. Psychopharmacology 152: 283-288.

Hirsch SR, Das I, Garey LJ, deBelleroche J (1997). A pivotal role for glutamate in the pathogenesis of schizophrenia, and its cognitive dysfunction. Pharmacol Biochem Behav 56: 797-802.

Javitt DC, Zukin SR (1991). Recent advances in the phencyclidine model of schizophrenia. Am J Psychiatry 148: 1301-1308.

Jentsch JD, Roth RH (1999). The neuropsychopharmacology of phencyclidine: from NMDA receptor hypofunction to the dopamine hypothesis of schizophrenia. Neuropsychopharmacology 20: 201-225.

Jonides J, Schumacher EH, Smith EE, Lauber EJ, Awh E, Minoshima $S$ et al (1997). Verbal working memory load affects regional brain activation as measured by PET. J Cognitive Neurosci 9: 462-475.

Joyce E, Hutton S, Mutsatsa S, Gibbins H, Webb E, Paul S et al (2002). Executive dysfunction in first-episode schizophrenia and relationship to duration of untreated psychosis: the West London Study. Br J Psychiatry 181(Suppl 43): S38-S44.

Kharasch ED, Labroo R (1992). Metabolism of ketamine stereoisomers by human liver microsomes. Anesthesiology 77: 1201-1207.

Krystal JH, Abi-Dargham A, Laruelle M, Moghaddam B (1999). Pharmacologic models of psychoses. In: Charney DS, Nestler EJ,
Bunney BS (eds). Neurobiology of Mental Illness. Oxford University Press: New York. pp 214-224.

Krystal JH, Bennett A, Abi-Saab D, Belger A, Karper LP, D’Souza DC et al (2000). Dissociation of ketamine effects on rule acquisition and rule implementation: possible relevance to NMDA receptor contributions to executive cognitive functions. Biol Psychiatry 47: 137-143.

Krystal JH, Karper LP, Seibyl JP, Freeman GK, Delaney R, Bremner JD et al (1994). Subanesthetic effects of the noncompetitive NMDA antagonist, ketamine, in humans. Arch Gen Psychiatry 51: 199-214.

Lahti AC, Koffel B, LaPorte D, Tamminga CA (1995). Subanesthetic doses of ketamine stimulate psychosis in schizophrenia. Neuropsychopharmacology 13: 9-19.

Lahti AC, Weiler MA, Michaelidis T, Parwani A, Tamminga CA (2001). Effects of ketamine in normal and schizophrenic volunteers. Neuropsychopharmacology 25: 455-467.

LaPorte DJ, Lahti AC, Koffel B, Tamminga CA (1996). Absence of ketamine effects on memory and other cognitive functions in schizophrenic patients. J Psychiatric Res 30: 321-330.

Mahurin RK, Velligan DI, Miller AL (1998). Executive-frontal lobe cognitive dysfunction in schizophrenia: a symptom subtype analysis. Psychiatry Res 79: 139-149.

Malhotra AK, Pinals DA, Adler CM, Elman I, Clifton A, Pickar D et al (1997). Ketamine-induced exacerbation of psychotic symptoms and cognitive impairment in neuroleptic-free schizophrenics. Neuropsychopharmacology 17: 141-150.

Malhotra AK, Pinals DA, Weingartner H, Sirocco K, Missar CD, Pickar D et al (1996). NMDA receptor function and human cognition: the effects of ketamine in healthy volunteers. Neuropsychopharmacology 14: 301-307.

Manoach DS, Gollub RL, Benson ES, Searl MM, Goff DC, Halpern E et al (2000). Schizophrenic subjects show aberrant fMRI activation of dorsolateral prefrontal cortex and basal ganglia during working memory performance. Biol Psychiatry 48: 99-109.

McGrath J, Scheldt S, Welham J, Clair A (1997). Performance on tests sensitive to impaired executive ability in schizophrenia, mania and well controls: acute and subacute phases. Schizophr Res 26: 127-137.

Morice R, Delahunty A (1996). Frontal/executive impairments in schizophrenia. Schizophr Bull 22: 125-137.

Nelson HE (1991). National Adult Reading Test. NFER-Nelson Publishing: Berkshire, UK.

Newcomer JW, Farber NB, Jevtovic-Todorovic V, Selke G, Melson AK, Hershey T et al (1999). Ketamine-induced NMDA receptor hypofunction as a model of memory impairment and psychosis. Neuropsychopharmacology 20: 106-118.

Owen AM, Downes JJ, Sahakian BJ, Polkey CE, Robbins TW (1990). Planning and spatial working memory following frontal lobe lesions in man. Neuropsychologia 28: 1021-1034.

Owen AM, Evans AC, Petrides M (1996). Evidence for a two-stage model of spatial working memory processing within the lateral frontal cortex: a positron emission tomography study. Cereb Cortex 6: 31-38.

Owen AM, Sahakian BJ, Hodges JR, Summers BA, Polkey CE, Robbins TW (1995). Dopamine-dependent frontostriatal planning deficits in early Parkinson's disease. Neuropsychology 9: $126-140$

Petrides M (1998). Specialized systems for the processing of mnemonic information within the primate frontal cortex. In: Roberts AC, Robbins TW, Weiskrantz L (eds). The Prefrontal Cortex: Executive and Cognitive Functions. Oxford University Press: Oxford, UK. pp 103-116.

Petrides M, Alivisatos B, Meyer E, Evans AC (1993). Functional activation of the human frontal cortex during the performance of verbal working memory tasks. Proc Natl Acad Sci USA 90: $878-882$. 
Radant AD, Bowdle A, Cowley DS, Kharasch ED, Roy-Byrne PP (1998). Does ketamine-mediated $N$-methyl-D-aspartate receptor antagonism cause schizophrenia-like oculomotor abnormalities. Neuropsychopharmacology 19: 434-444.

Randolph C (1998). RBANS: Repeatable Batter for the Assessment of Neuropsychological Status. Psychological Corporation: San Antonio, TX.

Robbins TW, James M, Owen AM, Sahakian BJ, McInnes L, Rabbitt $P$ (1994). Cambridge Neuropsychological Test Automated Battery (CANTAB): a factor analytic study of a large sample of normal elderly volunteers. Dementia 5: 266-281.

Sahakian BJ, Owen AM (1992). Computerized assessment in neuropsychiatry using CANTAB: discussion paper. J R Soc Med 85: 399-402.

Smith EE, Jonides J, Koeppe RA (1996). Dissociating verbal and spatial working memory using PET. Cereb Cortex 6: 11-20.

Stone M, Gabrieli JDE, Stebbins GT, Sullivan EV (1998). Working and strategic memory deficits in schizophrenia. Neuropsychology 12: $278-288$.

Tamminga CA (1998). Schizophrenia and glutamatergic transmission. Crit Rev Neurobiol 12: 21-36.

Tek C, Gold J, Blaxton T, Wilk C, McMahon RP, Buchanan RW (2002). Visual perceptual and working memory impairments in schizophrenia. Arch Gen Psychiatry 59: 146-153.

Volz HP, Gaser C, Hager F, Rzanny I, Ponisch J, Mentzel HJ et al (1999). Decreased frontal activation in schizophrenics during stimulation with the Continuous Performance Test-a functional magnetic resonance imaging study. Eur Psychiatry 14: $17-24$.

Wing JK, Cooper JE, Sartorius N (1974). The Measurement and Classification of Psychiatric Symptoms. Cambridge University Press: Cambridge, UK. 